\title{
Maternal and perinatal outcome in women with threatened abortion in first trimester
}

\author{
Meenal S. Sarmalkar*, Shashibala Singh, Arun H. Nayak
}

Department of Obstetrics and Gynaecology, Lokmanya Tilak Municipal Medical College \& General Hospital, Sion, Mumbai, Maharashtra, India

Received: 22 February 2016

Accepted: 18 March 2016

\section{*Correspondence:}

Dr. Meenal S. Sarmalkar,

E-mail: meenal.sarmalkar@gmail.com

Copyright: (c) the author(s), publisher and licensee Medip Academy. This is an open-access article distributed under the terms of the Creative Commons Attribution Non-Commercial License, which permits unrestricted non-commercial use, distribution, and reproduction in any medium, provided the original work is properly cited.

\section{ABSTRACT}

Background: Threatened abortion in first trimester is a risk factor for complications in the latter half of pregnancy. The present study was undertaken to identify the pregnancy outcome in women with threatened abortion in the first trimester of pregnancy in a tertiary hospital.

Methods: A retrospective-prospective observational study was done on 100 pregnant women with a history of threatened abortion in the first trimester. Maternal outcome in the form of pregnancy loss, APH/PPH, Preeclampsia/eclampsia, PROM/PPROM, term delivery and retained placenta were studies. Perinatal outcome in the form of preterm delivery, Low Birth Weight, IUGR and IUFD were studied. Analysis of the data was done using SPSS version 17.

Results: Threatened abortion in first trimester was found to be associated with increased risks of LBW, preterm births, PPROM, and PIH. Out of 100 patients, preterm births and LBW babies were found in $21 \%$ and $13 \%$ of patients respectively. $15 \%$ of the cases developed $\mathrm{PIH}$, out of which gestational hypertension and pre-eclampsia were $8 \%$ and $6 \%$ respectively.

Conclusions: Pregnant women with first trimester threatened abortion are at increased risk for spontaneous loss and adverse pregnancy outcomes. Knowledge of these risks may help the obstetricians to manage these cases vigorously in the antepartum period and do timely interventions as needed for a healthy mother and baby.

Keywords: Threatened Abortion, First trimester, Pregnancy

\section{INTRODUCTION}

Threatened abortion refers to any vaginal bleeding in the first 20 weeks of pregnancy, without cervical dilatation or passage of the products of conception, whether or not this bleeding is associated with uterine contractions. ${ }^{1}$ According to available data, threatened abortion is seen in $20-25 \%$ of all pregnancies. ${ }^{1}$ The diagnosis of threatened abortion is frequently made in clinical practice by history of vaginal spotting and the finding of a closed cervix on subsequent vaginal examination. A definitive diagnosis of threatened abortion needs documentation of fetal cardiac activity following ultrasonographic examination. $^{2}$
Many studies suggest that first-trimester vaginal bleeding has an association with bad pregnancy outcome. ${ }^{3,4}$ An increased risk of poor obstetric outcomes such as preterm labour, low birth weight, and premature rupture of membranes has been noted in such patients. ${ }^{5-7}$

In order to understand other risks of first-trimester bleeding, we evaluated the incidence of a variety of placental and non-placental outcomes such as pregnancy loss, preterm delivery, intrauterine growth restriction (IUGR), preeclampsia, preterm premature rupture of membranes (PPROM), placental abruption, placenta praevia, and caesarean delivery in pregnancies with firsttrimester bleeding. 


\section{METHODS}

This was a retrospective-prospective observational study undertaken in the Department of Obstetrics and Gynaecology of a tertiary care hospital in Mumbai, Maharashtra, India. It was conducted over a period of 15 months from March 2013 to May 2014. After taking written informed consent, a total of 100 patients of threatened abortion during first twelve weeks of gestation admitted from OPD or in labour ward were studied after considering inclusion and exclusion criteria. All patients in the age group 19-40 yrs and with gestational age less than 12 weeks with viability confirmed on ultrasound were included. Patients who were unwilling for registration, previous history of $>3$ abortions, hydatidiform mole, multiple pregnancies, local lesions of cervix and vaginal and uterine anomalies were excluded. Also patients with medical disorders e.g. hypothyroidism, diabetes mellitus, chronic hypertension, diagnosed thrombophilias and other bleeding disorders were also excluded.

The subjects for the retrospective component were drawn from a cohort of pregnant females who came to the OPD or labour ward for obstetric care. Medical records for each obstetric patient were evaluated retrospectively for any history of bleeding per vaginum during first 12 weeks of pregnancy. Subsequent pregnancy events for retrospective cases were recorded by questioning patients and following up their antenatal file. The prospective patients who arrived to OPD/labour ward with complaints of bleeding per vaginum were booked and followed up. A detailed history was taken including age, parity, duration of onset of bleeding, amount of blood loss and its association with pain. Clinical, systemic and gynaecological examination was done on each patient. Routine and special investigations like ultrasound (pelvis) were done to confirm fetal cardiac activity. The patients were admitted and closely monitored along with supportive therapy in the form of progesterone. Once their symptoms subsided, they were discharged and called in the OPD as per scheduled antenatal visits.

Each patient was monitored during and after labour. Following facts were noted during postpartum period:

- APGAR score at 1 and 5 minutes, birth weight, sex, congenital anomalies, immediate complications like birth injuries, signs of asphyxia, meconium aspiration, sepsis and other associated complications were recorded.

- Episiotomy wound and caesarean section wound was observed and regular follow-up was done.

- Maternal morbidity like puerperal sepsis, urinary and respiratory tract infection, breast engorgement, tenderness and wound infection were looked for.

Outcomes were categorized broadly into maternal and perinatal outcomes.
Maternal outcomes included were abortion, preeclampsia, eclampsia, gestational hypertension, antepartum haemorrhage (APH, Placenta praevia, abruption, other causes of APH), PPROM/PROM, term delivery, mode of delivery (Instrumental and Caesarean Deliveries), Postpartum Haemorrhage (PPH) and Retained Placenta.

The perinatal outcomes included preterm delivery (delivery before 37completed weeks), low birth weight (birth weight $\leq 2000 \mathrm{~g}$ ), IUGR and IUFD.

The statistical analysis was done using SPSS Software Version-17. All the qualitative data were presented as frequency and percentages and were compared using Fisher's test or Chi-square test. All the quantitative data were presented as means and standard deviation and were compared using t-test or analysis of variance (multiple group comparisons). The $\mathrm{p}$ value of $<0.05$ was considered as significant.

\section{RESULTS}

A total of 100 patients were studied as regards their demographic characteristics, maternal and fetal outcomes.

Table 1: Age wise distribution of subjects.

\begin{tabular}{|ll|}
\hline \multicolumn{1}{|c|}{ Age (in years) } & \\
\hline Mean & 26.1 \\
\hline Median & 26.0 \\
\hline Mode & 25.0 \\
\hline Std. Deviation & 3.4 \\
\hline Minimum & 20.0 \\
\hline Maximum & 38.0 \\
\hline
\end{tabular}

Table 2: Description of age.

\begin{tabular}{|lll|}
\hline Age (in years) & No of patients $(\mathbf{N}=\mathbf{1 0 0})$ & $\%$ \\
\hline $20-25$ yrs & 47 & 47 \\
\hline $26-30$ yrs & 41 & 41 \\
\hline $31-35$ yrs & 11 & 11 \\
\hline$>36$ yrs & 1 & 1 \\
\hline Total & 100 & 100 \\
\hline
\end{tabular}

Table 3: Distribution of subjects on the basis of gravidity and parity.

\begin{tabular}{|llll|}
\hline Obstetric History & N & $\%$ \\
\hline \multirow{5}{*}{ Gravida } & 1 & 52 & 52.0 \\
\cline { 2 - 4 } & 2 & 30 & 30.0 \\
\cline { 2 - 4 } & 3 & 16 & 16.0 \\
\hline \multirow{3}{*}{ Para } & 4 & 2 & 2.0 \\
\cline { 2 - 4 } & Total & 100 & 100.0 \\
\hline & 1 & 36 & 36.0 \\
\cline { 2 - 4 } & 2 & 2 & 2.0 \\
\cline { 2 - 4 } & Total & 38 & 38.0 \\
\hline
\end{tabular}


Table 4: Mean period of gestation at first episode of bleeding (entire cohort).

\begin{tabular}{|ll|}
\hline Mean & Admitted at (days) \\
\hline Median & 58.0 \\
\hline Mode & 55.0 \\
\hline Std. Deviation & 58.0 \\
\hline Minimum & 11.9 \\
\hline Maximum & 37.0 \\
\hline
\end{tabular}

Table 1 show that the mean age of the patient in the study group was 26.1 yrs. \pm 3.4 . Also women between $20-25$ yrs age group constituted the largest $(47 \%)$ number of cases (Table 2).

Table 3 shows that most patients were primigravida $(52 \%)$ and $48 \%$ patients were multigravida.

Table 4 shows that the mean period of gestation at the first episode of bleeding was 58 days \pm 11.9 .

Table 5: Analysis of period of gestation at delivery according to gravidity.

\begin{tabular}{|c|c|c|c|c|c|c|}
\hline \multicolumn{7}{|c|}{ Period of gestation at delivery (in days) } \\
\hline Period of gestation (days) & $\mathrm{N}$ & Mean & Std. Deviation & Minimum & Maximum & $\mathrm{p}$-value \\
\hline G1 & 52 & 257.3 & 20.7 & 190 & 284 & \multirow{5}{*}{0.73} \\
\hline G2 & 30 & 261.2 & 29.0 & 137 & 284 & \\
\hline G3 & 16 & 263.3 & 13.1 & 235 & 284 & \\
\hline G4 & 2 & 266.0 & 17.0 & 254 & 278 & \\
\hline Total & 100 & 259.6 & 22.4 & 137 & 284 & \\
\hline
\end{tabular}

Table 5 shows mean period of gestation (POG) at the time of delivery as per gravidity and parity. The mean period of gestation at the time of delivery was 257.3 , $261.2,263.3$ and 266 days in primigravida, $2^{\text {nd }}, 3^{\text {rd }}$ and $4^{\text {th }}$ gravida respectively. There was no significant difference $(\mathrm{P}=0.73)$ in the period of gestation at time of delivery based on the gravidity of the patient.

Table 6: Type of delivery in the cohort.

\begin{tabular}{|lll|}
\hline Type of delivery & $\mathbf{N}$ & $\%$ \\
\hline FTND & 29 & 29.0 \\
\hline LSCS & 38 & 38.0 \\
\hline Pre-term delivery & 21 & 21.0 \\
\hline Forceps delivery & 4 & 4.0 \\
\hline Aborted & 7 & 7.0 \\
\hline IUFD & 1 & 1.0 \\
\hline Total & 100 & 100.0 \\
\hline
\end{tabular}

Table 6 shows that $29 \%$ of delivered normally and $38 \%$ underwent elective or emergency caesarean section. $21 \%$ had preterm delivery.

Table 7: Type of LSCS.

\begin{tabular}{|lll|}
\hline LSCS & N & $\%$ \\
\hline Elective & 15 & 39.5 \\
\hline Emergency & 23 & 60.5 \\
\hline
\end{tabular}

Table 7 shows the number of patients who underwent Caesarean section in the assigned group. Total 38 patients underwent LSCS out of which 15 were elective and 23 were emergency LSCS due to fetal or maternal indications.

Table 8: Analysis of indications of LSCS.

\begin{tabular}{|ll|}
\hline Indication & Number \\
\hline Malpresentation & 4 \\
\hline Previous LSCS & 4 \\
\hline Placenta Praevia & 2 \\
\hline Non progress of labour (NPOL) & 7 \\
\hline Failure of induction & 3 \\
\hline Fetal distress & 7 \\
\hline PPROM & 1 \\
\hline Abruption & 1 \\
\hline CPD & 1 \\
\hline Eclampsia & 1 \\
\hline MSAF & 3 \\
\hline Severe oligohydramnios & 1 \\
\hline Severe PE & 3 \\
\hline
\end{tabular}

Table 8 shows that NPOL and Fetal distress were the most common indications for which LSCS had been done.

Table 9 shows maternal and perinatal outcomes in a pregnancy complicated by threatened abortion. The most common antenatal complication was preterm premature rupture of membranes (11\%) followed by gestational hypertension $(8 \%)$ and pre-eclampsia $(8 \%)$. Spontaneous abortion and PPH was found in $7 \%$ cases each. Only $1 \%$ patients had abruption placentae and eclampsia each. (Table 10).In fetal outcome, preterm delivery was highest (21\%) followed by LBW babies $(13 \%)$. 
Table 9: Analysis of maternal and fetal outcomes after threatened abortion.

\begin{tabular}{|lll|}
\hline Outcomes $(\mathbf{n = 1 0 0})$ & N & $\%$ \\
\hline Maternal & 7 & 7.00 \\
\hline Pregnancy loss (abortion) & 1 & 1.00 \\
\hline Abruptio placentae & 2 & 2.00 \\
\hline Placenta praevia & 7 & 7.00 \\
\hline PPH & 3 & 3.00 \\
\hline PROM & 11 & 11.00 \\
\hline PPROM & 6 & 6.00 \\
\hline Preeclampsia & 1 & 1.00 \\
\hline Eclampsia & 8 & 8.00 \\
\hline Gestational HT & 2 & 2.00 \\
\hline Retained placenta & 1 & 1.00 \\
\hline Oligohydramnios & & \\
\hline Fetal & 5 & 5.00 \\
\hline Fetal distress & 21 & 21.0 \\
\hline Pre-term delivery & 13 & 13.0 \\
\hline Low birth weight $(<=2 \mathrm{~kg})$ & 6 & 6.0 \\
\hline IUGR & 1 & 1.0 \\
\hline IUFD & 3 & 3.00 \\
\hline Meconium stained liquor & 2 & 2.00 \\
\hline Malpresentation & & \\
\hline
\end{tabular}

Table 10: Birth weight of new-born babies.

\begin{tabular}{|lll|}
\hline Birth weight $(\mathrm{Kg})$ & Number & $\%$ \\
\hline$<1.5$ & 5 & 5.3 \\
\hline $1.6-2.0$ & 8 & 8.6 \\
\hline $2.1-2.5$ & 25 & 26.8 \\
\hline $2.6-3.0$ & 32 & 34.4 \\
\hline $3.1-3.5$ & 19 & 20.4 \\
\hline $3.6-4$ & 4 & 4.3 \\
\hline
\end{tabular}

Table 10 shows the birth weight of the new born baby with mean new-born weight being $2.5 \mathrm{~kg}$. The maximum number of babies fell in the category of $2.6-3.0 \mathrm{kgs}$. Out of all the babies born, 21 were kept in NICU for more than 48 hours due to either LBW or prematurity.

Table 11: Analysis of weight of new-born.

\begin{tabular}{|ll|}
\hline \multicolumn{2}{|c|}{ New-born weight (in kgs) } \\
\hline Mean & 2.5 \\
\hline Median & 2.7 \\
\hline Mode & 2.9 \\
\hline Std. Deviation & 0.8 \\
\hline Minimum & 0.25 \\
\hline Maximum & 3.9 \\
\hline
\end{tabular}

Table 11 shows that the mean new-born weight in the study group was found to be $2.5 \mathrm{~kg} \pm 0.8$.
Table 12: Analysis of babies according to birth weight.

\begin{tabular}{|lll|}
\hline New born weight $(\mathrm{Kg})$ & $\mathrm{N}$ & $\%$ \\
\hline$<2.5$ & 34 & 36.95 \\
\hline$\geq 2.5$ & 58 & 63.05 \\
\hline
\end{tabular}

Table 12 shows that $63 \%$ babies weighed $\geq 2.5 \mathrm{kgs}$ whereas only $36.9 \%$ weighed $<2.5$.

Table 13: Analysis of Apgar score among the newborn.

\begin{tabular}{|lll|}
\hline APGAR $(\mathrm{n}-92)$ & $\mathrm{N}$ & $\%$ \\
\hline$\leq 7$ & 36 & 39.1 \\
\hline$>7$ & 56 & 60.9 \\
\hline
\end{tabular}

Table 13 shows that the Apgar score was more than 7 in $60 \%$ of new-borns when the mother had an incident of bleeding before 12 weeks of gestation.

Table 14: Analysis of neonatal outcome.

\begin{tabular}{|lll|}
\hline Neonatal outcome $(\mathbf{n = 9 2})$ & $\mathbf{N}$ & $\%$ \\
\hline Healthy & 62 & 67.4 \\
\hline Birth asphyxia & 5 & 5.4 \\
\hline HIE & 4 & 4.3 \\
\hline MSAF & 3 & 3.3 \\
\hline RDS & 12 & 13.0 \\
\hline PNM & 5 & 5.4 \\
\hline Sepsis (NEC) & $6(2)$ & 6.5 \\
\hline IVH & 2 & 2.2 \\
\hline Jaundice & 1 & 1.1 \\
\hline ROP & 1 & 1.1 \\
\hline
\end{tabular}

Table 14 shows the neonatal health at birth in the entire cohort. 62 babies were born healthy and free of complications. Respiratory distress was seen in 12 of the cases, one fetus underwent intrauterine death and 5 newborns with medical complications had died postnatally. Jaundice, sepsis, MASF and asphyxia were seen in 15 of the new-borns.

Table 15: Maternal complications post-delivery.

\begin{tabular}{|lll|}
\hline Maternal complications & $\mathrm{N}$ & $\%$ \\
\hline Healthy & 72 & 72.0 \\
\hline Fever & 9 & 9.0 \\
\hline PPH & 7 & 7.0 \\
\hline UTI & 3 & 3.0 \\
\hline MROP & 2 & 2.0 \\
\hline Wound infection & 6 & 6.0 \\
\hline PRES & 1 & 1.0 \\
\hline
\end{tabular}

Table 15 shows maternal complications causing significant morbidity occurred in at least 28 mothers. Fever was the most common postnatal maternal complication which was seen in 9 mothers. 


\section{DISCUSSION}

Pregnancy is a major life event. The purpose of pregnancy is to develop a healthy baby and keep the mother healthy. Threatened abortion is an adverse event during pregnancy, which needs meticulous attention to fulfil the purpose of pregnancy.

Our data show that threatened miscarriage is associated with adverse pregnancy outcomes. Results from this study confirm findings from other authors, that threatened abortion is associated with an increased risk of certain pregnancy-related complications, namely placental abruption, preterm labour, delivery of low birth weight infants and PPROM. ${ }^{8,9,13}$ Generally, high incidence of abortion and complications in threatened miscarriage indicate the necessity of proper programming in care and also educating high risk women. Results of this study support other evidence that, in some patients, firsttrimester vaginal bleeding may indicate underlying placental dysfunction, which may be manifest in later pregnancy by a variety of adverse outcomes that have also been related to placental dysfunction.

\section{Abortion}

The incidence of abortion in the present study was 7\%. A previous study done by Agarwal et al found an incidence of $21 \%$ in 62 patients with a history of threatened abortion in first twenty weeks of pregnancy. ${ }^{9}$ Another study by Ahmed et al. showed the incidence of abortion in 85 patients with bleeding in first twenty weeks of pregnancy to be $17 \% .{ }^{10}$ The lower rate of abortion in our study could be attributed to the fact that we have included only first trimester threatened abortion. Moreover, all our included subjects had confirmed ultrasound fetal viability. In such subjects, Tongsong et al have shown the incidence of abortion to be closer to $4-5 \%$ which corresponds with our study. ${ }^{11}$ Everett et al also found an incidence of $5 \%$ abortion rate in subjects with threatened abortion who had documented sonographic fetal cardiac activity. $^{12}$

\section{PPROM}

In our study, incidence of PROM/PPROM was $14 \%$ while a study done by Davari-Tanha et al had $16 \%$ of patients with PPROM. ${ }^{13}$ Another study by Hossain et al showed incidence of PPROM in cases with first trimester complications as $4.19 \% .{ }^{14}$ Our findings corroborate other studies that suggested an association between threatened abortion and PPROM. ${ }^{15-17}$ Although the cause is unclear, it is hypothesized that disruption of the chorionicamniotic plane by adjacent haemorrhage may make the membranes more susceptible to rupture. ${ }^{17}$ Alternatively, the prolonged presence of blood may act as a nidus for intrauterine infection. Persistent or recurrent placental haemorrhage could also stimulate subclinical uterine contractions that result in cervical change and eventual ruptured membranes.

\section{Preterm birth}

Incidence of preterm birth in our study it was $21 \%$ while in a study done by Arafa et al. showed an incidence of $26.19 \% .^{18}$ The association between vaginal bleeding and preterm delivery has also been noted by others. ${ }^{19}$ Both Batzofin et al and Williams et al reported that patients with bleeding had double the risk of preterm delivery compared with patients without bleeding. ${ }^{17,20}$ The study of Williams et al. was limited to first trimester bleeding. ${ }^{20}$ Batzofin et al. included patients with bleeding up to 20 weeks. ${ }^{17}$ Strobino and Pantel-Silverman failed to show an association between preterm delivery before 36 weeks of gestation with light vaginal bleeding in the first or second trimester of pregnancy. ${ }^{21}$ Another study found that preterm delivery is increased significantly in patients with either light $(\mathrm{OR},<2.0)$ or heavy (OR, 3.0) firsttrimester bleeding. ${ }^{22}$ Despite significant advances in perinatal medicine, the incidence of preterm delivery has remained unchanged. The prediction of preterm delivery from currently available methods is unreliable; therefore, associated risk factors remain an important measure of identifying at-risk pregnancies. ${ }^{21,23}$

\section{Low birth weight}

The risk of low birth weight in our group of patients was $13 \%$ while in a similar study by Batzofin et al., the incidence of LBW was $15.48 \%{ }^{17}$ A further study by Sheiner et al found the risk of LBW in women with first trimester bleeding and no previous history of abortion to be $9.7 \% .^{24}$ Davari-Tanha et al also found risk of Low Birth Weight to be $14.9 \%$ in their study. ${ }^{13}$

\section{Intrauterine fetal death}

We had one case of IUFD in our study. Dongol et al. reported 3 cases of IUFD out of 70 in their study. ${ }^{25}$

\section{Intrauterine growth restriction}

There were varying reports as regards intrauterine growth restriction is concerned among various groups. A study done by Arafa et al. reported an incidence of $48.5 \%$ while another study done by Davari-Tanha revealed an incidence of $2 \% .^{13,18}$ In our study, the incidence of IUGR was found to be $6 \%$.

\section{Pregnancy induced hypertension}

In 1993, Verma et al reported that pregnancy induced hypertension was significantly more common in subjects with threatened abortion and a viable pregnancy compared with subjects without vaginal bleeding (6\% vs. $4.7 \%$, respectively; $\mathrm{p}<0.05) .{ }^{26}$ However, their study was limited by a total of only 113 subjects. Another study by Wilcox et al. did not find an association between firsttrimester vaginal bleeding and gestational hypertension but did find that patients with light bleeding were statistically more likely to have preeclampsia. ${ }^{27}$ This 
association carried a low OR of <2.0. In our study, the incidence of gestational hypertension and pre-eclampsia were $8 \%$ and $6 \%$ respectively. In addition, one case of full blown eclampsia was also noted in our cohort.

\section{Placental abruption}

Many studies reported that patients with first-trimester threatened abortion are at increased risk for placental abruption and IUGR. ${ }^{23}$ Placental haemorrhage may recur later in pregnancy, which results in placental abruption. In our study, the risk of abruption was $1 \%$. Other studies like done by Davari-Tanha and Mulik et al showed similar results. 13,28

\section{Placenta praevia}

Our results revealed incidence of placenta praevia as $2 \%$ in the study population. The study done by Davari-Tanha revealed an incidence of $0.66 \%$ at the same time Konje et al reported an incidence of $4.1 \% .^{13,29}$ The location of the chorion frondosum within the uterine cavity in early pregnancy may explain this association, with an inferior position more likely to cause first-trimester bleeding, as well as a higher risk of placenta praevia later on in pregnancy. Das et al reported an increased risk for a lowlying placenta among women with threatened miscarriage but found no difference in placental location compared with control subjects by 36 weeks of gestation. ${ }^{8}$ Weiss et al. found a similar association that was not statistically significant. ${ }^{30}$ Mulik et al found a significantly higher risk of placenta praevia at 37 weeks in women who experienced a first-trimester vaginal bleed. ${ }^{28}$

\section{Manual removal of placenta}

The incidence of manual removal of placenta was found to be higher among women with threatened miscarriage. Hertz and Heisterberg reported that retention of placenta was associated with threatened miscarriage, and the rate of manual removal was $14 \% .^{3}$ They postulated that adhesive scarring between the uterine wall and the placenta at the site of bleeding might be responsible for the increased incidence of retention of placenta in women with threatened miscarriage. In our study, the rate of manual removal was found to be $2 \%$ which was not significant.

\section{Term delivery}

Term delivery was seen in $71 \%$ of cases in our study. Out of these, 29 had vaginal delivery while rest had either instrumental or caesarean delivery. Ben Haroush et al found the incidence of term delivery in threatened abortion to be $86.5 \%$ which was similar to our results. ${ }^{31}$ Dongol et al. found the incidence of term delivery in cases of threatened abortion to be up to $75.8 \%$ in their study. $^{25}$

\section{Caesarean section}

Data linking caesarean delivery to threatened miscarriage are very limited. Our study showed an incidence of $38 \%$ LSCS in this cohort, out of which $23(23 \%)$ were done for emergency indications. This is similar to the findings of Weiss et al which showed no evidence of an association with emergency caesareans. ${ }^{30}$ Caesarean delivery rate in the above mentioned study was $25.6 \%$.

\section{Instrumental delivery}

The risk of instrumental (forceps) delivery was not significantly altered in our study. Only $4 \%$ of deliveries needed forceps application. Out of which 3 were for maternal exhaustion and 1 was for arrest in second stage. A study done by Mulik et al revealed incidence to be $21.1 \%$ which could be due to large sample size taken for the study and use of instrument for the delivery of a distressed fetus. ${ }^{28}$

Results from these studies \& our study confirm findings from other authors, that threatened abortion is associated with an increased risk of certain pregnancy-related complications, namely abortion, placental abruption, preterm labour, delivery of low birth weight infants and PPROM. ${ }^{8,30}$ Generally, high incidence of abortion and adverse pregnancy outcomes in threatened miscarriage indicate the necessity of proper programming in care and also educating high risk women.

\section{CONCLUSION}

The current study reports that patients with first-trimester threatened abortion are at a risk for spontaneous pregnancy loss and adverse pregnancy outcomes. For patients who reported vaginal bleeding during the first trimester, high risks of abortion (7\%), LBW (13\%), preterm delivery (21\%), PPROM (14\%), PIH (15\%) placental abruption (1\%), and low lying placenta $(2 \%)$ were observed. These associations are clinically significant since they denote increased morbidity and mortality.

Results of the current study validate previous studies which support the school of thinking that first-trimester vaginal bleeding may indicate underlying placental dysfunction, which may manifest in later pregnancy by a variety of adverse outcomes including preterm delivery, pregnancy induced hypertension, placental abruption and fetal growth restriction. Conversely, since preterm delivery is associated with threatened miscarriage, identifying women who are at "high risk" for preterm labour is very important. Knowledge of this increased risk may also facilitate decision making regarding management, for example, timely administration of corticosteroids or decisions regarding mode, place, and timing of delivery, which will inevitably improve neonatal outcome. Because the overall prognosis is favourable, these results can also be used to help reassure 
patients with threatened abortion during the first trimester. At the same time, obstetricians should be aware of the adverse outcomes that are associated with firsttrimester bleeding and remain alert for signs of these complications.

\section{ACKNOWLEDGEMENTS}

I would like to express my profound gratitude to all the participants for their co-operation and for their immense faith they reposed in me.

\section{Funding: No funding sources}

Conflict of interest: None declared

Ethical approval: The study was approved by the Institutional Ethics Committee

\section{REFERENCES}

1. Cunningham F, Leveno K, Bloom S, Hauth J, Rouse D, Spong C. Williams Obstetrics: 23rd Edition. 23rd ed: McGraw-Hill Education. 2009:215-226.

2. Park IY, Shin JC, Kim CY. Prognosis Of Threatened Abortion By Embryonic/Fetal Heart Beat Rate. Ultrasound In Obstetrics And Gynecology. 2006;28(4):482.

3. Hertz JB, Heisterberg L. The Outcome Of Pregnancy After Threatened Abortion. Acta Obstetricia Et Gynecologica Scandinavica. 1985;64(2):151-6.

4. Batzofin JH, Fielding WL, Friedman EA. Effect Of Vaginal Bleeding In Early Pregnancy On Outcome. Obstetrics And Gynecology. 1984;63(4):515-8.

5. Williams MA, Mittendorf R, Lieberman E, Monson RR. Adverse Infant Outcomes Associated With FirstTrimester Vaginal Bleeding. Obstetrics And Gynecology. 1991;78(1):14-8.

6. Bennett GL, Bromley B, Lieberman E, Benacerraf BR. Subchorionic Hemorrhage In First-Trimester Pregnancies: Prediction Of Pregnancy Outcome With Sonography. Radiology. 1996;200(3):803-6.

7. Sipila P, Hartikainen-Sorri AL, Oja H, Von Wendt L. Perinatal Outcome Of Pregnancies Complicated By Vaginal Bleeding. British Journal Of Obstetrics And Gynaecology. 1992;99(12):959-63.

8. Das AG, Gopalan S, Dhaliwal LK. Fetal Growth And Perinatal Outcome Of Pregnancies Continuing After Threatened Abortion. The Australian \& New Zealand Journal Of Obstetrics \& Gynaecology. 1996;36(2):135-9.

9. Agrawal S, Khoiwal, S., Jayant, K., Agarwal, R. Predicting Adverse Maternal And Perinatal Outcome After Threatened Miscarriage. Open Journal Of Obstetrics And Gynecology. 2014;4(1):1-7.

10. Ahmed SR, El-Sammani Mel K, Al-Sheeha MA, Aitallah AS, Jabin Khan F, Ahmed SR. Pregnancy Outcome In Women With Threatened Miscarriage: A Year Study. Materia Socio-Medica. 2012;24(1):26-8.

11. Tongsong $\mathrm{T}$, Srisomboon $\mathrm{J}$, Wanapirak $\mathrm{C}$, Sirichotiyakul S, Pongsatha S, Polsrisuthikul T. Pregnancy Outcome Of Threatened Abortion With
Demonstrable Fetal Cardiac Activity: A Cohort Study. Journal Of Obstetrics And Gynaecology. 1995;21(4):331-5.

12. Everett CB, Preece E. Women With Bleeding In The First 20 Weeks Of Pregnancy: Value Of General Practice Ultrasound In Detecting Fetal Heart Movement. The British Journal Of General Practice : The Journal Of The Royal College Of General Practitioners. 1996;46(402):7-9.

13. Davari-Tanha F, Shariat M, Kaveh M, Ebrahimi M, Jalalvand S. Threatened Abortion: A Risk Factor For Poor Pregnancy Outcome. Acta Medica Iranica. 2008;46(4):314-320.

14. Hossain R, Harris T, Lohsoonthorn V, Williams MA. Risk Of Preterm Delivery In Relation To Vaginal Bleeding In Early Pregnancy. European Journal Of Obstetrics, Gynecology, And Reproductive Biology. 2007;135(2):158-63.

15. Farrell T, Owen P. The Significance Of Extrachorionic Membrane Separation In Threatened Miscarriage. British Journal Of Obstetrics And Gynaecology. 1996;103(9):926-8.

16. Chung TK, Sahota DS, Lau TK, Mongelli JM, Spencer JA, Haines CJ. Threatened Abortion: Prediction Of Viability Based On Signs And Symptoms. The Australian \& New Zealand Journal Of Obstetrics \& Gynaecology. 1999;39(4):443-7.

17. Batzofin JH, Fielding WL, Friedman EA. Effect Of Vaginal Bleeding In Early Pregnancy On Outcome. Obstetrics And Gynecology. 1984;63(4):515-8.

18. Arafa M, Abdel-Fataah M, Zeid HA, el-Khouly A. Outcomes Of Pregnancies Complicated By Early Vaginal Bleeding. Eastern Mediterranean Health Journal. 2000;6(2-3):457-64.

19. Makikallio K, Tekay A, Jouppila P. Uteroplacental Hemodynamics During Early Human Pregnancy: A Longitudinal Study. Gynecologic And Obstetric Investigation. 2004;58(1):49-54.

20. Williams MA, Mittendorf R, Lieberman E, Monson RR. Adverse infant outcomes associated with firsttrimester vaginal bleeding. Obstetrics and Gynecology. 1991;78(1):14-8.

21. Strobino BA, Pantel-Silverman J. First-Trimester Vaginal Bleeding And The Loss Of Chromosomally Normal And Abnormal Conceptions. American Journal Of Obstetrics And Gynecology. 1987;157(5):1150-4.

22. Wilcox AJ, Weinberg CR, O'Connor JF, Baird DD, Schlatterer JP, Canfield RE, et al. Incidence Of Early Loss Of Pregnancy. The New England Journal Of Medicine. 1988;319(4):189-94.

23. Norwitz ER, Schust DJ, Fisher SJ. Implantation And The Survival Of Early Pregnancy. The New England Journal Of Medicine. 2001;345(19):1400-8.

24. Sheiner E, Levy A, Katz M, Mazor M. Pregnancy Outcome Following Recurrent Spontaneous Abortions. European Journal Of Obstetrics \& Gynecology And Reproductive Biology. 2005;118(1):61-5. 
25. Dongol A, Mool S, Tiwari P. Outcome Of Pregnancy Complicated By Threatened Abortion. Kathmandu University Medical Journal (KUMJ). 2011;9(33):414.

26. Verma SK, Premi HK, Gupta TV, Thakur S, Gupta KB, Randhawa I. Perinatal Outcome Of Pregnancies Complicated By Threatened Abortion. Journal Of The Indian Medical Association. 1994;92(11):364-5.

27. Wilcox AJ, Weinberg CR, O'Connor JF, Baird DD, Schlatterer JP, Canfield RE, et al. Incidence Of Early Loss Of Pregnancy. The New England Journal Of Medicine. 1988;319(4):189-94.

28. Mulik V, Bethel J, Bhal K. A Retrospective Population-Based Study Of Primigravid Women On The Potential Effect Of Threatened Miscarriage On Obstetric Outcome. Journal Of Obstetrics And
Gynaecology : The Journal Of The Institute Of Obstetrics And Gynaecology. 2004;24(3):249-53.

29. Konje JC, Ewings PD, Adewunmi OA, Adelusi B, Ladipo OA. The Outcome Of Pregnancies Complicated By Threatened Abortion. Journal Of Obstetrics \& Gynaecology. 1992;12(3):150-5.

30. Weiss JL, Malone FD, Vidaver J, Ball RH, Nyberg DA, Comstock $\mathrm{CH}$, et al. Threatened abortion: A Risk Factor For Poor Pregnancy Outcome, A Population-Based Screening Study. American Journal Of Obstetrics And Gynecology. 2004;190(3):745-50.

31. Ben-Haroush A, Yogev Y, Mashiach R, Meizner I. Pregnancy Outcome Of Threatened Abortion With Subchorionic Hematoma: Possible Benefit Of BedRest? The Israel Medical Association Journal : IMAJ. 2003;5(6):422-4.

Cite this article as: Sarmalkar MS, Singh S, Nayak AH. Maternal and perinatal outcome in women with threatened abortion in first trimester. Int $\mathrm{J}$ Reprod Contracept Obstet Gynecol 2016;5:1438-45. 